\title{
A new approach to fabricate superconducting NbTi alloys
}

\author{
Tayebeh Mousavi ${ }^{1,2}$, Zuliang Hong ${ }^{1}$, Alasdair Morrison ${ }^{1}$, Andrew London ${ }^{1}$, \\ Patrick S Grant ${ }^{1}$, Chris Grovenor ${ }^{1,2}$, Susie Speller ${ }^{1,2}$ \\ ${ }^{1}$ Materials Department, Oxford University, 16 Parks Road, OX1 3PH, Oxford, UK \\ ${ }^{2}$ Centre for Applied Superconductivity, Materials Department, Oxford University
}

\begin{abstract}
Superconducting NbTi alloys have been successfully fabricated by a simple powder processing route involving ball-milling, pressing and annealing. The microstructure and superconducting properties of the NbTi alloys after each processing step have been characterized and compared to the microstructure and performance of NbTi wire manufactured by a conventional thermomechanical process.
\end{abstract}

At the early stages of milling, a lamellar structure of pure $\mathrm{Nb}$ and $\mathrm{Ti}$ regions is formed, which is gradually refined by further milling leading to the introduction of a high density of microstructural defects. After 20 hrs milling, diffusion of Ti into the $\mathrm{Nb}$ generates a matrix of $\beta$-Nb-50wt\% Ti alloy, with a small grain size $(50 \mathrm{~nm})$ and high strain $(1.8 \%)$, containing an even distribution of thin Ti flakes $(10-40 \mathrm{~nm})$. In some regions, these Ti flakes contain a supersaturation of $\mathrm{Nb}$ as a result of the energetic ball-milling process. The $\mathrm{T}_{\mathrm{c}}(8.1 \mathrm{~K})$ and $\mathrm{B}_{\mathrm{c} 2}$ $(9.8 \mathrm{~T}$ at $4.2 \mathrm{~K})$ values of this as-milled material are slightly lower than those reported for $\mathrm{Nb}$ $47 \mathrm{wt} \% \mathrm{Ti}$ due to the impurity content and lattice disorder. Sintering at $400{ }^{\circ} \mathrm{C}$ leads to well consolidated, high density bulk samples, but annealing at temperatures above $600{ }^{\circ} \mathrm{C}$ decreases $\mathrm{J}_{\mathrm{c}}$ values due to excessive grain growth and strain release. Annealing at lower temperatures results in higher $\mathrm{J}_{\mathrm{c}}$ values, a shift of the pinning force density peak towards higher fields and the presence of thermodynamically stable $\alpha$-Ti precipitates which are effective pinning sites leading to critical current density values comparable with those of commercial NbTi wires. 
Keywords: Powder processing, NbTi superconducting alloys, Ball-milling, Mechanical alloying

\section{1- Introduction}

The $\mathrm{Nb}$-Ti alloy system has been the dominant commercial superconductor used for magnet windings since the 1960 s because of its strength and ductility, high critical current density, and relatively low cost [1]. The main applications of $\mathrm{NbTi}$ based magnets are in Magnetic Resonance Imaging (MRI), Nuclear Magnetic Resonance (NMR), Superconducting Magnetic Energy Storage (SMES) and particle accelerators [1][2][3]. In all of these applications, a carefully tailored microstructure is needed in the $\mathrm{NbTi}$ alloy filaments in order to optimise the critical current carrying capacity in high magnetic fields. High purity, a fine grain structure and reasonable ductility are essential requirements in the starting alloy [1][4]. In addition, as in all type II superconductors, achieving high critical current densities in magnetic fields is only possible if flux line motion is inhibited. In commercial NbTi wires, strong pinning is achieved by the precipitation of finely dispersed, nanometer scale $\alpha$-Ti grains, the separation of which closely matches the spacing of magnetic flux lines characteristic of the magnetic field in which the superconductor is going to operate $[5][6][7]$. When considering any alternative process to fabricate NbTi alloys, it is thus necessary to be able to generate a uniform fine dispersion of nanoscale $\alpha$-Ti precipitates, which can only be achieved if, in addition to the requirements above, the starting alloy has excellent chemical homogeneity over both the macro and micro scales [8].

In almost all commercial $\mathrm{NbTi}$ wires this has been achieved using a starting composition of $\mathrm{Nb}-47 \mathrm{wt} \% \mathrm{Ti}$ which has a high ductility and, after thermomechanical processing, results in an optimised combination of high $\mathrm{B}_{\mathrm{c} 2}$ and $\mathrm{T}_{\mathrm{c}}$ values, and the correct volume of nanoscale $\alpha$-Ti to maximise $J_{c}$ values. This thermomechanical processing route is rather complex, involving 
fabricating large $\mathrm{NbTi}$ billets by vacuum arc melting of pure $\mathrm{Nb}$ and Ti electrodes, then drawing and annealing under carefully controlled conditions [1]. During the drawing process a high cold work strain is induced, followed by three or more heat treatments in the $\alpha+\beta$ phase range, each separated by additional cold work [8][9]. In all of these steps, it is important that the processing conditions, including annealing temperature and strain, are precisely controlled in order to generate the optimized microstructure required for practical applications [10][11][12]. As a result this process is difficult and expensive, in part because of the high sensitivity of the final microstructure to the chemical uniformity of the initial alloy billet which controls the local microstructure after the final drawing and annealing operations [8]. One of the most difficult steps is the production of the initial alloy billet, mainly because of the wide separation of the solidus and liquidus in the $\mathrm{Nb}$ - $\mathrm{Ti}$ phase diagram, which results in severe micro-segregation in melt-processed alloys.

The aim of this work is to explore an alternative processing method to fabricate bulk NbTi alloys with very high compositional uniformity, taking inspiration from numerous examples of powder metallurgy being used to reduce micro-segregation in complex engineering alloys [13] [14]. We have chosen high energy ball-milling of solid-state powders as the processing route because of its demonstrated potential in the fabrication of fine-grained alloys at relatively low temperatures by mechanical alloying [15][16][17]. Ball-milling induces repeated welding, fracturing and re-welding of powder particles, leading to a very fine microstructure, a high degree of residual strain, a high concentration of lattice defects and accelerated inter-diffusion between starting components which make it possible to fabricate alloys at low temperatures. In general it is also an inexpensive processing technique with a high uniformity in the final product [18]. All of these characteristics are required to generate the special microstructure required for optimised superconducting NbTi alloys. Moreover, the ductile-ductile combination of $\mathrm{Nb}$ and $\mathrm{Ti}$ starting powders is what is needed to achieve effective mechanical 
alloying by ball milling [15]. There have been a small number of reports on ball-milling of alloys in the $\mathrm{Nb}$-Ti system, but all of these have focused on producing $\mathrm{Ti}(\mathrm{Nb})$ alloys with better mechanical properties for biomedical applications [19][20]. This work focuses on the fabrication and characterization of superconducting NbTi alloys by powder processing, and comparisons are made between the superconducting properties of in-house $\mathrm{NbTi}$ and those of conventionally processed wires.

\section{2- Experimental Details}

A mixture of high-purity elemental powders of $\mathrm{Nb}$ (purity: 99.85\%, Goodfellow) and $\mathrm{Ti}$ (purity: 99.5\%, Goodfellow) with nominal composition of $\mathrm{Nb}-47 \mathrm{wt} \%$ Ti was sealed together with 200 stainless steel balls (10 $\mathrm{mm}$ in diameter) in a cylindrical steel pot under an argon atmosphere. The ball-to-powder weight ratio was 10:1. The milling pot was loaded onto a Fristsch P6 planetary ball mill and rotated at a $200 \mathrm{rpm}$ at room temperature in cycles of 20minute milling followed by 15-minute rest to cool down the system. By using this process, no significant heating of the powder was noticed during ball milling. After selected intervals of milling time (10, 15, 20, 30, 40, 50 and $60 \mathrm{hrs}), 1 \mathrm{~g}$ samples were extracted in an Ar glove-box for characterization.

The $40 \mathrm{~h}$-milled powder was hot-pressed into a $20 \mathrm{~mm}$-disc at $400^{\circ} \mathrm{C}, 40 \mathrm{MPa}$ and $5 \times 10^{-4} \mathrm{mbar}$ followed by annealing in evacuated quartz tubes $\left(10^{-4} \mathrm{mbar}\right)$ for $2 \mathrm{hrs}$ at different temperatures $\left(350,600\right.$ and $\left.1100^{\circ} \mathrm{C}\right)$.

After each of these processing steps, the samples were characterized by a number of techniques, including x-ray diffraction (XRD), Scanning Electron Microscopy (SEM), Transmission Electron Microscopy (TEM), Atom Probe Tomography and SQUID magnetometry. The XRD measurements were carried out in a Rigaku Miniflex diffractometer using $\mathrm{Cu}_{\mathrm{k} \alpha}$ radiation $(\lambda=0.154 \mathrm{~nm})$ at $40 \mathrm{kV}$ and $15 \mathrm{~mA}$. The grain size and lattice strain were calculated from the 
broadening of the XRD peaks using Williamson-Hall equations [21]. For this calculation, the instrumental broadening was removed by assuming a Gaussian profile and using $\mathrm{Nb}$ powder with large crystallite size as a standard material.

The SEM analysis was carried out using a JEOL 5510 SEM with OI SDD detector operating at $20 \mathrm{kV}$ accelerating voltage. Higher spatial-resolution chemical analysis was performed using a Zeiss Merlin SEM with an Oxford Instruments (OI) $150 \mathrm{~mm}^{2}$ XMax EDX detector on thinfoil samples (thickness $<200 \mathrm{~nm}$ ) in order to minimize beam broadening effects. Both these thin foils and TEM samples were made using the ex-situ lift-out technique by Focused Ion Beam (FIB) milling, and TEM analysis was performed on a JEOL 3000F TEM.

The atom probe tomography (APT) data was acquired on a LEAP 3000X HR (Imago, USA) in laser pulsing mode with a $0.5 \mathrm{~nJ}$ pulse energy of a $532 \mathrm{~nm}$ laser, $200 \mathrm{kHz}$ pulse frequency, $0.2 \%$ evaporation rate and $50 \mathrm{~K}$ specimen temperature. Atom probe data was reconstructed using Cameca IVAS ${ }^{\mathrm{TM}}$ version 3.6.14 using the voltage curve reconstruction method with an effective field of $26 \mathrm{~V} / \mathrm{nm}$, k-factor of 3.3 and image compression factor of 1.65 . Atom probe samples were prepared from the bulk mirror-polished samples using FIB methods [22]. For the bulk milling and tip sharpening a $30 \mathrm{kV}$ Ga beam was used, but the final milling step was made using a $2 \mathrm{kV}$ accelerating voltage and $300 \mathrm{pA}$ current to limit $\mathrm{Ga}^{+}$ion penetration into the sample.

Superconducting properties were measured using a Quantum Design SQUID magnetometer and Physical Property Measurement System (PPMS). The critical current density $\left(\mathrm{J}_{\mathrm{C}}\right)$ values were extracted from the full magnetic hysteresis loops using Bean's model [23] with the selffield correction. We have treated our $2 \mathrm{~mm}$ cube samples as a cylinder $\left(J_{C}=\frac{1.5 \mathrm{\Delta m}}{\pi r^{3} l}\right)$, where $m$ is the magnetic moment and $r$ and $l$ (the radius and length of the cylinder) are both taken to be $2 \mathrm{~mm}$. In order to have a closer comparison with the transport $\mathrm{J}_{\mathrm{c}}$ values of multifilamentary wires, 4-point transport measurements were carried out using a digital Glassman BPI 1200A 
DC current source in liquid He in fields up to $12 \mathrm{~T}$. For this measurement, a thin ribbon (thickness $\sim 120 \mu \mathrm{m}$ ) was prepared by multi-pass cold rolling some of the hot pressed bulk NbTi sample with three intermediate annealing steps at $400{ }^{\circ} \mathrm{C}$ for $2 \mathrm{hrs}$, and a total thickness reduction of $95 \%$. The ribbon was then coated with electrodeposited $\mathrm{Cu}$ in order to provide a surface on which low resistance contacts could be made with indium solder for the transport measurements.

\section{3- Results and Discussion}

\section{3-1-Powder Processing}

Figure 1 shows typical back-scattered SEM images from cross-sections of individual powder particles after different milling times. This imaging mode is sensitive to average atomic mass, so the dark and bright regions represent Ti-rich and $\mathrm{Nb}$-rich regions respectively. After $10 \mathrm{hrs}$ of milling the powder particles consist of a layered structure of alternating $\mathrm{Nb}$ and $\mathrm{Ti}$, Figure 1(a). With further milling, this layered microstructure becomes finer, such that after $40 \mathrm{hrs}$ distinct $\mathrm{Nb}$ and $\mathrm{Ti}$ layers are no longer easily resolved, Figure 1(e). As we expect with a ductile-ductile mixture, in the early stages of the milling of the $\mathrm{Nb}$-Ti system the initial pure $\mathrm{Nb}$ and $\mathrm{Ti}$ particles are first flattened to platelet/pancake shapes which are then cold-welded together to form the observed composite lamellar structure of $\mathrm{Nb}$ and $\mathrm{Ti}$. As a result of this cold-welding process, the average particle size increases with milling time from $200 \mu \mathrm{m}$ after $10 \mathrm{hrs}$ to $800 \mu \mathrm{m}$ after $40 \mathrm{hrs}$. The summary of these observations in Figure 1(f) shows that ball-milling of the $\mathrm{Nb}-\mathrm{Ti}$ system results in a gradual increase in particle size but refinement of the $\mathrm{Nb}$ and $\mathrm{Ti}$ distribution. Similar microstructural changes have been reported during milling of Nb-Ti system [24] and other ductile-ductile systems such as Ag-Cu [15] and Ni-Ti [17]. 

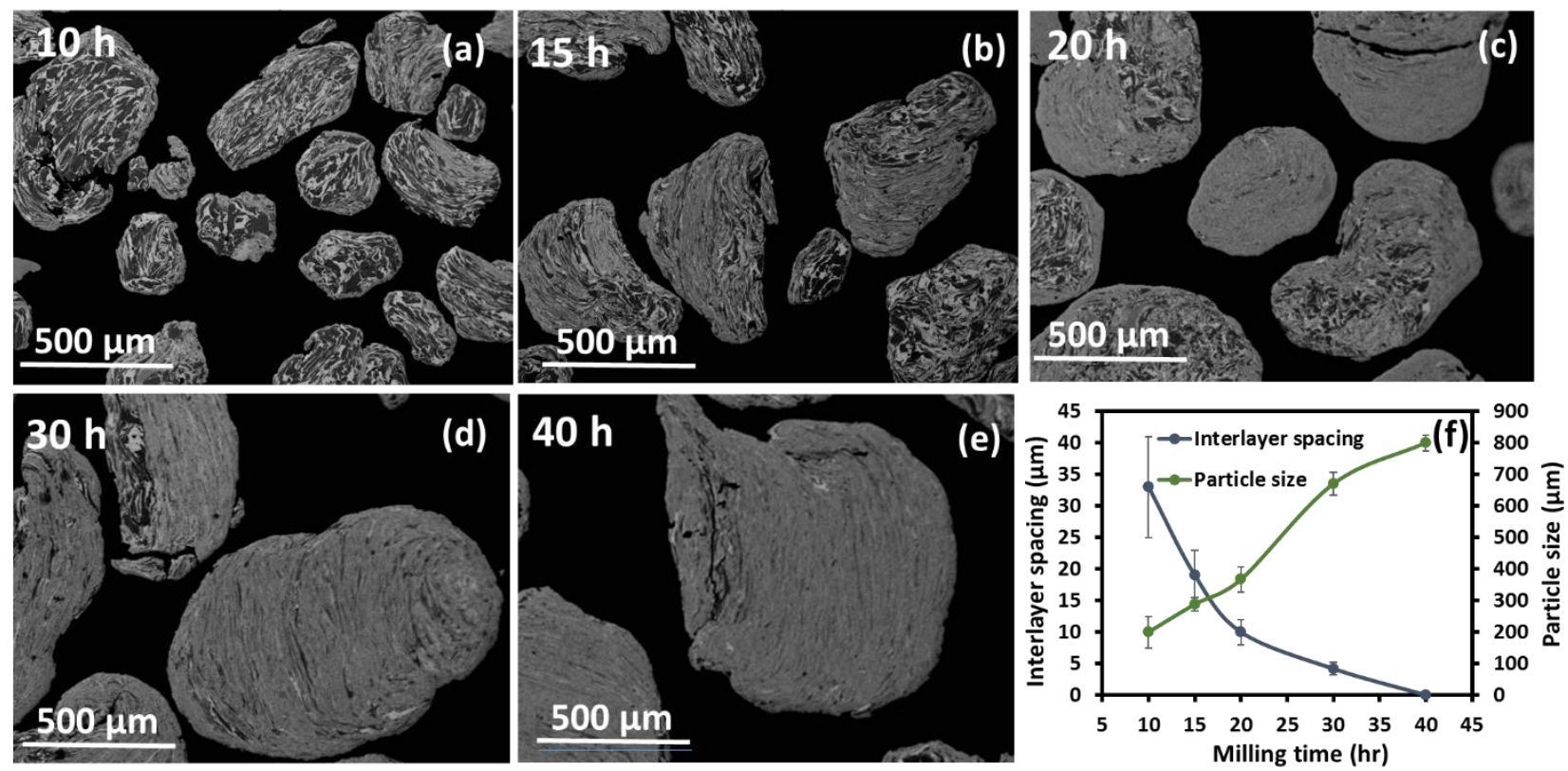

Figure 1: (a-e) Back-scattered SEM images from the cross-sections and (f) the interlayer spacing of the lamellar structure and the particle size of the $\mathrm{Nb}$-Ti powders after different milling times.

Typical $\mathrm{Nb}$ and Ti EDX maps and EDX line scan of powder particles after different milling times are shown in Figure $2 \mathrm{a}$ and $\mathrm{b}$ respectively. For milling times up to $15 \mathrm{hrs}$ a lamellar microstructure of nearly pure $\mathrm{Nb}$ and $\mathrm{Ti}$ layers is observed, with only very limited interdiffusion at this microstructural scale. However, as the milling time is increased, the interlamellar spacing is refined and the ball-milling process expands the mutual solubility limits of the elements. After $20 \mathrm{hrs}$ the Nb-rich matrix contains a significant Ti content, and the Ti-rich regions also contain some $\mathrm{Nb}$. For example, in addition to the nearly pure Ti regions (indicated by the arrows in Figure 2a), there are Ti-rich regions containing significant concentrations of $\mathrm{Nb}$ (Figure 2b), even though the phase diagram suggests that there is limited solubility of $\mathrm{Nb}$ in $\alpha$-Ti at room temperature [25]. The scale of this microstructure is sufficiently coarse to be confident that this apparent mechanical alloying is not just an artefact from beam broadening or from the interfaces lying inclined to the observation direction. The formation of thermodynamically unstable phases by ball-milling has also been reported in other systems such as $\mathrm{Cu}-\mathrm{Zn}[26]$ and $\mathrm{Ni}-\mathrm{Sn}[27]$. These results indicate that $\mathrm{Nb}(\mathrm{Ti})$ alloys are being 
formed at this stage of milling due to the combination of shorter interdiffusion distances and the fast diffusion paths resulting from the high density of structural defects created by the severe mechanical deformation during cold milling.
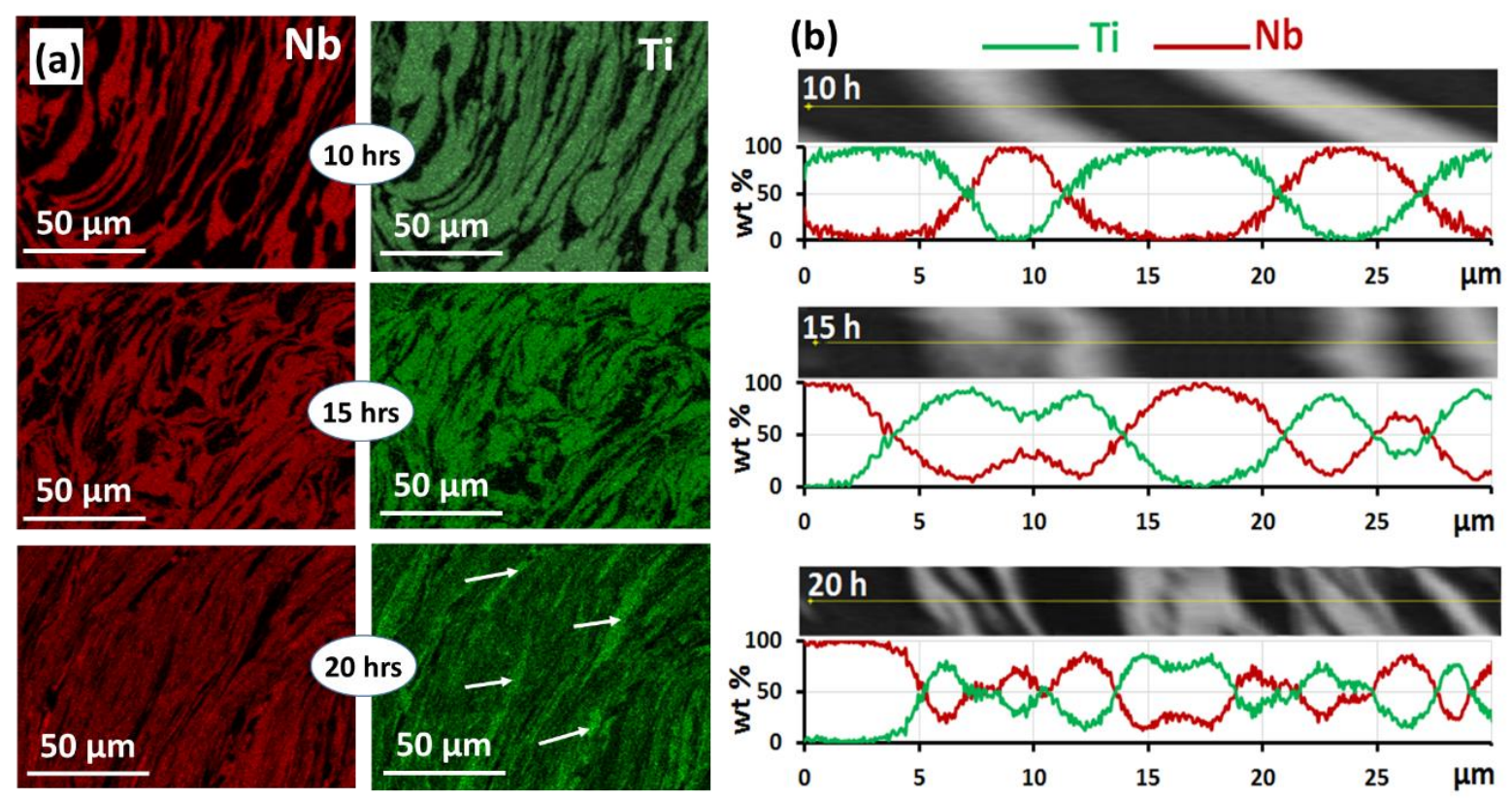

Figure 2: (a) SEM-EDX elemental maps for $\mathrm{Nb}$ and Ti after different milling times (The arrows identify pure Ti regions), (b) Back-scattered SEM images and SEM-EDX Nb and Ti concentration profiles along a 30- $\mu$ m scan-line of the powder after different milling times.

As shown in Figure 1, after $40 \mathrm{hrs}$ of milling the microstructure of the powder particles is rather uniform, and refined in scale sufficiently to require analysis by TEM at higher magnifications. As can be seen in the TEM images in Figure $3 b$ and $c$, the powder has a fine layered microstructure at a scale of 10-40 $\mathrm{nm}$. Chemical segregation of $\mathrm{Nb}$ and $\mathrm{Ti}$ in these layers can also be observed at the same scale in the EDX maps in Figure 3d and e (the EDX maps and line scan in Figure 3 are SEM data taken from a thin foil sample). The EDX line scan across these layers, Figure 3(f), clearly identifies alternating stripes of NbTi alloy and Ti-rich regions. The $\mathrm{NbTi}$ alloy layers have an average Ti content of about $50 \mathrm{wt} \% \pm 10$ and form a uniform matrix. The presence of fine Ti-rich stripes and a high concentration of phase boundaries formed by 
simple ball-milling for $40 \mathrm{hrs}$ is a promising start in producing a microstructure containing a high density of flux pinning sites.
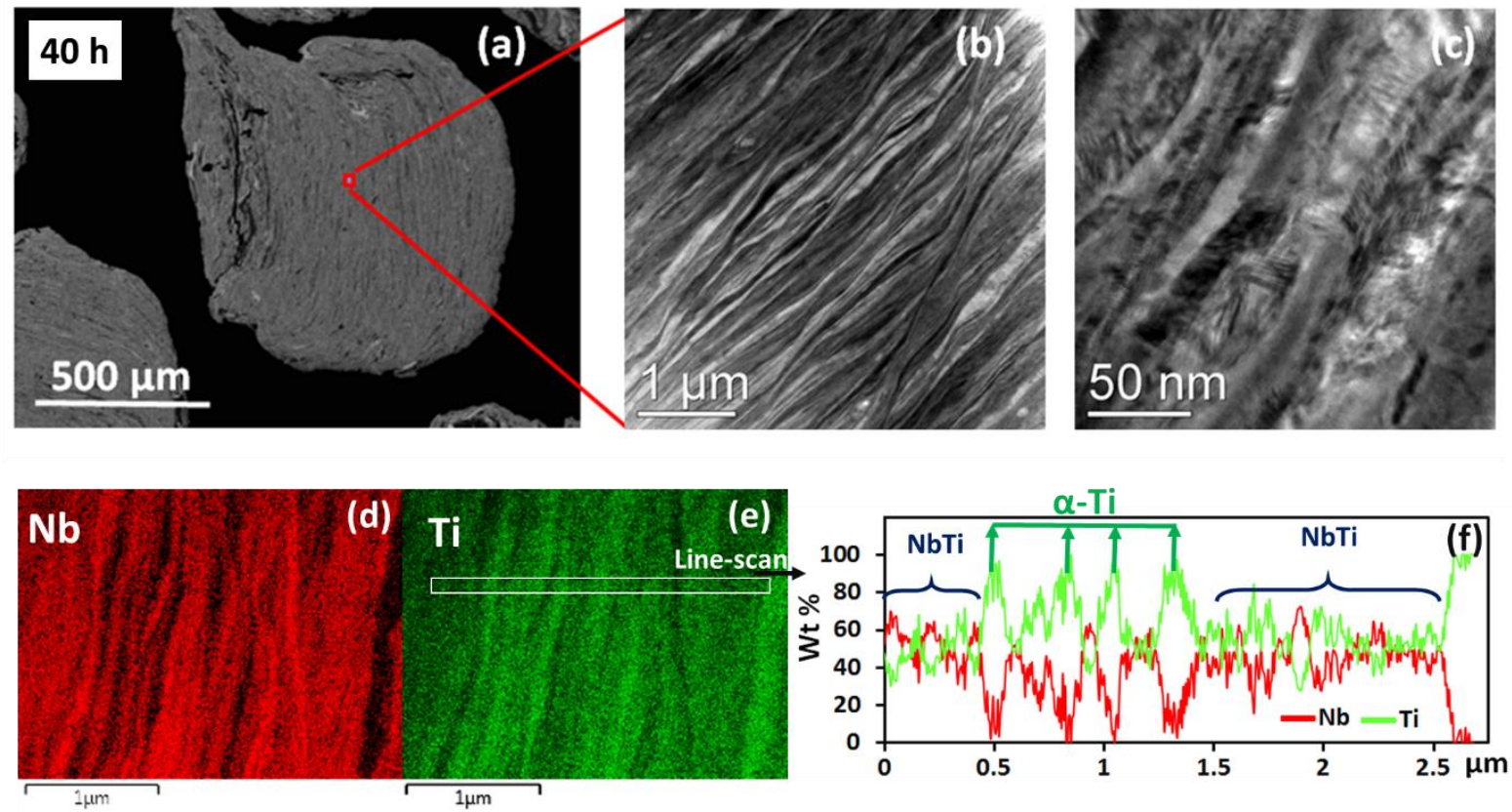

Figure 3: (a) Backscattered SEM image of 40hr-milled Nb-Ti powder, (b-c) Bright-field TEM images from the region identified at higher magnifications, (d-e) Nb and Ti EDX maps and (f) High magnification EDX line-scan of the area identified in (e). (The EDX maps and the EDX line scan were obtained in a Zeiss Merlin SEM from a thin TEM sample to minimize the contribution from beam spreading).

As is commonly observed, especially with ductile powders, the amount of powder recovered from the milling pot (powder yield) is influenced by milling time (Figure 4a). Up to $40 \mathrm{hrs,} \mathrm{the}$ powder yield decreases with increasing milling time, but surprisingly the yield apparently increases again for longer milling times. We suppose that up to $40 \mathrm{hrs}$ the ductile $\mathrm{Nb}$ and $\mathrm{Ti}$ powder particles are flattened, cold-welded and coated onto the surface of the milling media (both balls and pot) resulting in a reduction in powder yield. Conveniently, this $\mathrm{Nb}$-Ti coating prevents excessive wear of the milling media and avoids contamination of the powder, but as the thickness of the $\mathrm{Nb}$-Ti layer stuck to the milling media increases the powder yield decreases, such that after $40 \mathrm{hrs}$ only $20 \%$ of the initial powder is loose in the milling pot. For milling times longer than $40 \mathrm{hrs,} \mathrm{work-hardening} \mathrm{of} \mathrm{this} \mathrm{coating} \mathrm{layer} \mathrm{results} \mathrm{in} \mathrm{embrittlement}$ 
and fracture from the milling surfaces leading to an increase in the apparent powder yield. However, SEM analysis of powder after $60 \mathrm{hrs}$ milling shows that it is contaminated by particles eroded from the stainless steel milling media. As can be seen in the backscattered SEM image in Figure 4b, in addition to the regions of layered $\mathrm{Nb}$-Ti there are some relatively large particles confirmed by EDX to be rich in $\mathrm{Ni}, \mathrm{Cr}$ and $\mathrm{Fe}$.

We thus conclude that milling for more than $40 \mathrm{hrs}$ leads to impurities in the NbTi powder. For milling times below $40 \mathrm{hrs}$, the product has a reasonable purity but the powder yield is very low. It has been suggested the $\mathrm{Nb}$-Ti powder yield can be improved from $10 \%$ to $80 \%$ by using $2 \mathrm{wt} \%$ of $\mathrm{NaCl}$ as a process control agent [20], but the effect of $\mathrm{NaCl}$ on the purity of the final product is unclear. Using milling media made of harder materials like zirconia may also avoid introducing contamination into the powder and also achieve higher powder yield, but has not been investigated in this work.
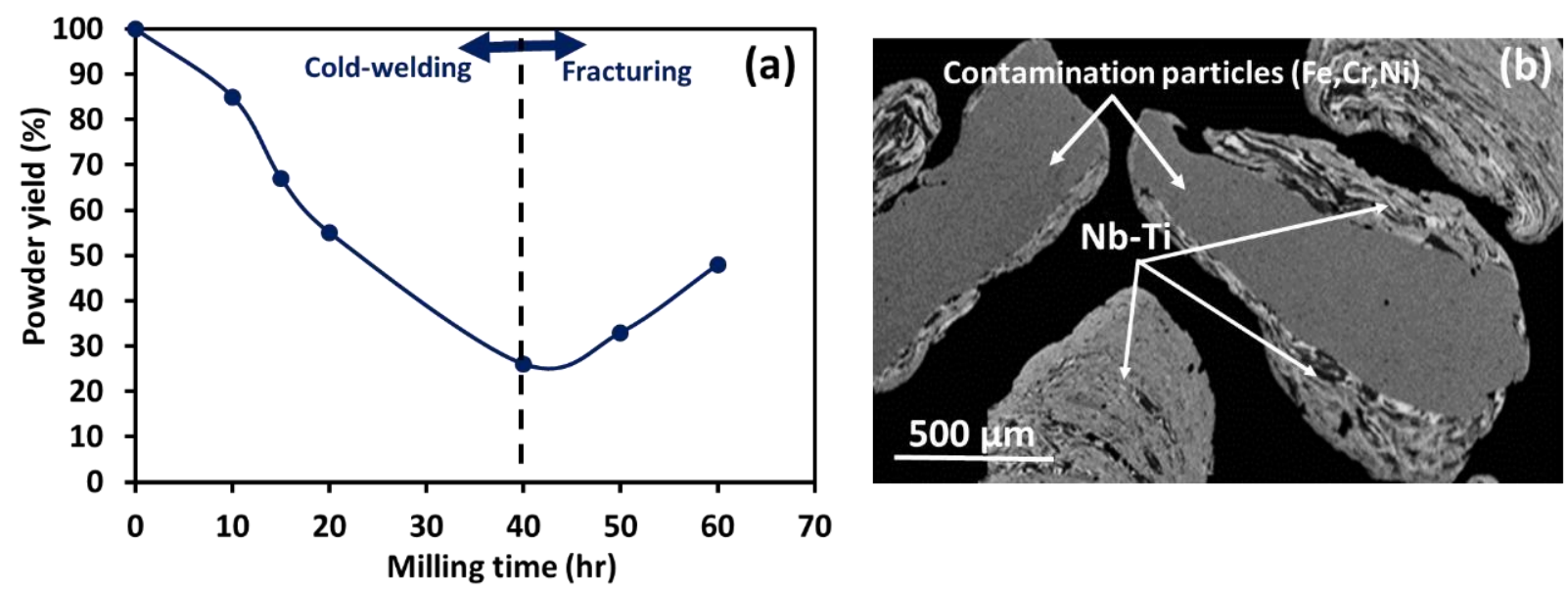

Figure 4: (a) Powder yield in the milling pot as a function of milling time, (b) Back-scattered SEM image of the cross-section of typical powder particles after 60 hrs milling.

In order to investigate the phase evolution during milling, XRD measurements were carried out on the powders after different milling times. As Figure 5 shows, after 20 hrs no $\alpha$-Ti peaks are detected in the XRD pattern whereas peaks at the initial position of pure $\mathrm{Nb}$ remain. The 
$\mathrm{Nb}$ - Ti binary phase diagram shows a continuous substitutional solid solution at high temperatures, with a body-centered cubic crystal structure $(\operatorname{Im} \overline{3} \mathrm{~m})$ across the whole composition range and a random distribution of $\mathrm{Nb}$ and $\mathrm{Ti}$ atoms in the unit cell [28]. However, at lower temperature we expect phase separation into $\beta-\mathrm{Nb}(\mathrm{Ti})$ and $\alpha-\mathrm{Ti}(\mathrm{Nb})$, and as the lattice parameter of $\mathrm{Nb}$ is not greatly affected by alloying with Ti the XRD peak positions for the $\beta$ $\mathrm{Nb}(\mathrm{Ti})$ alloy and pure $\mathrm{Nb}$ will be indistinguishable. The strong peaks at the positions of the metallic $\mathrm{Nb}$ peaks, even after extensive milling, together with the EDX results above, confirm that the effect of the milling process we have employed is to create $\beta-\mathrm{Nb}$ (Ti) at room temperature. In a similar study [29] single phase $\beta-\mathrm{Ti}(\mathrm{Nb})$ was formed in a $\mathrm{Ti}-35 \mathrm{Nb}-2.5 \mathrm{Sn}$ alloy by high energy ball-milling of elemental powders for only $12 \mathrm{hrs}$. We conclude from the combination of XRD and EDX analysis above that the disappearance of the $\alpha$-Ti peaks may be explained by the diffusion of $\mathrm{Nb}$ into $\mathrm{Ti}$ to form a $\beta$-Ti( $\mathrm{Nb}$ ) alloy with similar lattice parameter to the $\beta-\mathrm{Nb}(\mathrm{Ti})$, and identified as the Ti-rich regions in Figures 2 and 3. Any thin layers of $\alpha$-Ti still present in the microstructure are too narrow for strong coherent diffraction and are present at a small volume fraction making them hard to detect in the XRD patterns.

Moreover it can be seen in Figure 5 that milling leads to a broadening of the XRD peaks and a decrease in the peak intensity. We interpret this to be a result of grain size refinement and the introduction of lattice strain, both of which are a result of the severe mechanical deformation during milling [15]. Here we are taking grain size to mean the width of the lamellar structures in the SEM and TEM images above. After $40 \mathrm{hrs}$ of milling, the XRD pattern contains only broad $\beta-\mathrm{Nb}(\mathrm{Ti})$ peaks with no sign of either $\alpha$-Ti peaks or extra peaks from contamination/oxides. From the peak widths, values for the grain size and lattice strain in the $\mathrm{Nb}(\mathrm{Ti})$ powder have been calculated using the method described in the experimental section, and these are plotted as a function of milling time in Figure 6. By increasing the milling time, 
the grain size decreases and the lattice strain increases, with the major changes occurring between 15 and $30 \mathrm{hrs}$. The mechanical alloying process to form $\beta-\mathrm{Nb}(\mathrm{Ti})$ and $\beta-\mathrm{Ti}(\mathrm{Nb})$ is very effective at refining the grain size, and the high degree of strain is a result of the large concentration of crystalline defects and dislocations created by ball-milling as well as random substitution of $\mathrm{Ti}$ and $\mathrm{Nb}$ in metastable solid solutions. After $40 \mathrm{hrs}$ of milling, the grain size and lattice strain finally reach values of $\sim 50 \mathrm{~nm}$ and $1.8 \%$ respectively. The bright-field TEM image of this powder (Figure 3c) confirms a very fine microstructure with a similar spacing of planar regions and a high density of structural defects.

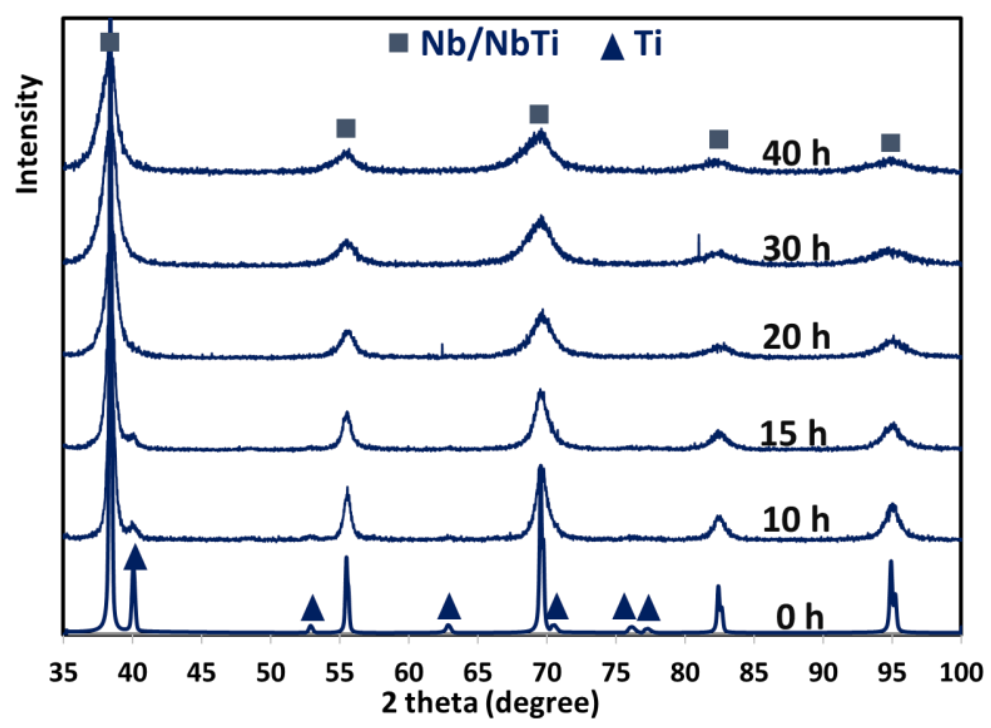

Figure 5: XRD patterns of the Nb-Ti powders after different milling times. 


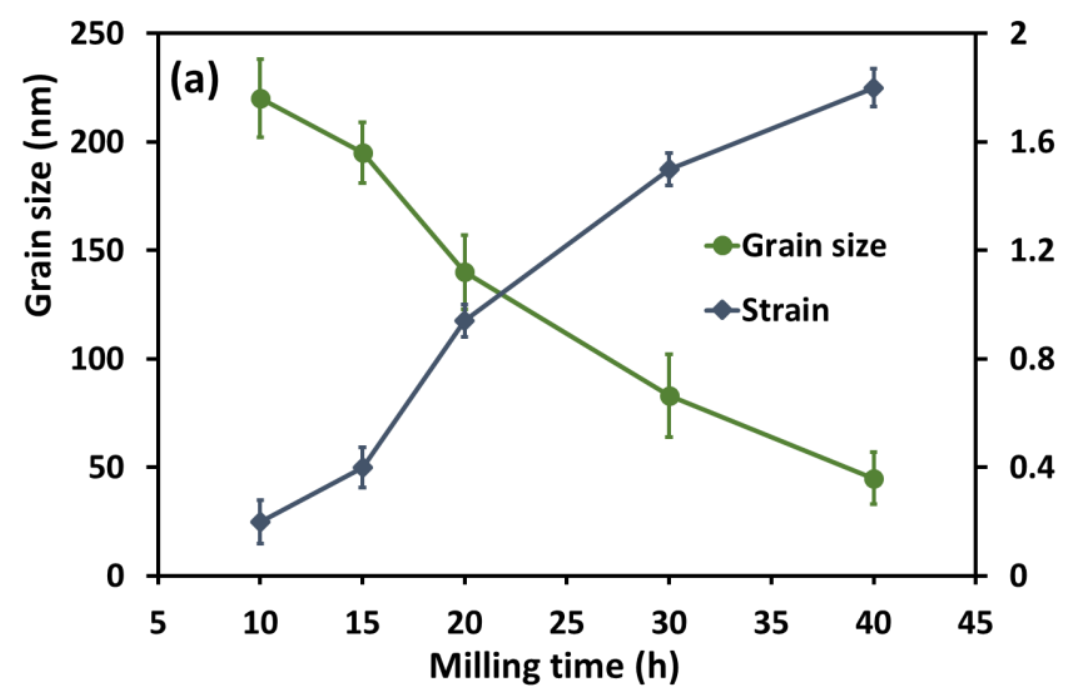

Figure 6: Grain size and lattice strain in Nb-Ti powders as a function of milling time extracted from the XRD data.

The superconducting properties of the $\mathrm{Nb}(\mathrm{Ti})$ powder after different milling times were measured using SQUID magnetometry. Figure $7 \mathrm{a}$ shows the extracted $\mathrm{B}_{\mathrm{c} 2}$ and $\mathrm{T}_{\mathrm{c}}$ values as a function of milling time. The initial powder (milling time=0), which is a mixture of pure $\mathrm{Nb}$ and $\mathrm{Ti}$ particles, exhibits a $\mathrm{T}_{\mathrm{c}}$ of about $8.9 \mathrm{~K}$ corresponding to pure $\mathrm{Nb}$. By increasing the milling time to $10 \mathrm{hrs}$ the $\mathrm{T}_{\mathrm{c}}$ value decreases, presumably due to the structural disorder and lattice strain introduced into the powder by ball-milling. It has been reported that lattice strain and disorder reduce the $\mathrm{T}_{\mathrm{c}}$ values in $\mathrm{Nb}$-Ti alloys [30]. Moreover, it is likely that the powder after 10hrs of ball-milling (even under argon) is not as pure as the initial $\mathrm{Nb}$, and so impurity pickup might be another reason for the reduction in $\mathrm{T}_{\mathrm{c}}$. Further increasing the milling time up to $40 \mathrm{hrs}$, when the powder consists mostly of the $\beta-\mathrm{Nb}$ (Ti) alloy, the $\mathrm{T}_{\mathrm{c}}$ values remain unchanged at $8.1 \mathrm{~K}$.

The $\mathrm{B}_{\mathrm{c} 2}$ values show a different trend, increasing with milling time as the $\mathrm{Nb}$ becomes alloyed with Ti. The literature $\mathrm{B}_{\mathrm{c} 2}$ values of pure $\mathrm{Nb}$ and $\mathrm{Nb}(\mathrm{Ti})$ are considerably different $\left(\mathrm{B}_{\mathrm{c} 2}\right.$ of pure $\mathrm{Nb}($ at $4.2 \mathrm{~K})=0.2 \mathrm{~T}, \mathrm{~B}_{\mathrm{c} 2}$ of $\mathrm{Nb}-47 \mathrm{wt} \% \mathrm{Ti}($ at $\left.4.2 \mathrm{~K})=11 \mathrm{~T}[1][9]\right)$, so the increase in $\mathrm{B}_{\mathrm{c} 2}$ with milling time in Figure 7 once again confirms the effective incorporation of Ti into the $\mathrm{Nb}$ lattice 
by mechanical deformation. Figure $7 b$ shows the $B_{c 2}$ values as a function of temperature for the $\mathrm{Nb}(\mathrm{Ti})$ powder after different milling times. At the early stages of milling, $\frac{d B_{C 2}}{d T}$ is low (about 0.2 ), but it increases with milling time to a value of 1.8 that approaches the $\frac{d B_{C 2}}{d T}$ value of 2 reported for $\mathrm{Nb}-47 \mathrm{wt} \% \mathrm{Ti}[31]$.

These initial properties for our powder-processed $\mathrm{Nb}$-Ti material look promising, but we note that the $\mathrm{T}_{\mathrm{c}}$ and $\mathrm{B}_{\mathrm{c} 2}$ values after $40 \mathrm{~h}$ milling $\left(\mathrm{T}_{\mathrm{c}}=8.1 \mathrm{~K}, \mathrm{~B}_{\mathrm{c} 2}(\right.$ at $\left.4.2 \mathrm{~K})=9.8 \mathrm{~T}\right)$ are lower than those reported for fully processed $\mathrm{NbTi}$ wires $\left(\mathrm{T}_{\mathrm{c}}=9.2 \mathrm{~K}, \mathrm{~B}_{\mathrm{c} 2}(\right.$ at $\left.4.2 \mathrm{~K})=11 \mathrm{~T}\right)[1]$. Contamination of the powder with oxygen or transition metals from the milling media and structural disorder are possible sources of this reduction, and would have to be explored in future work.
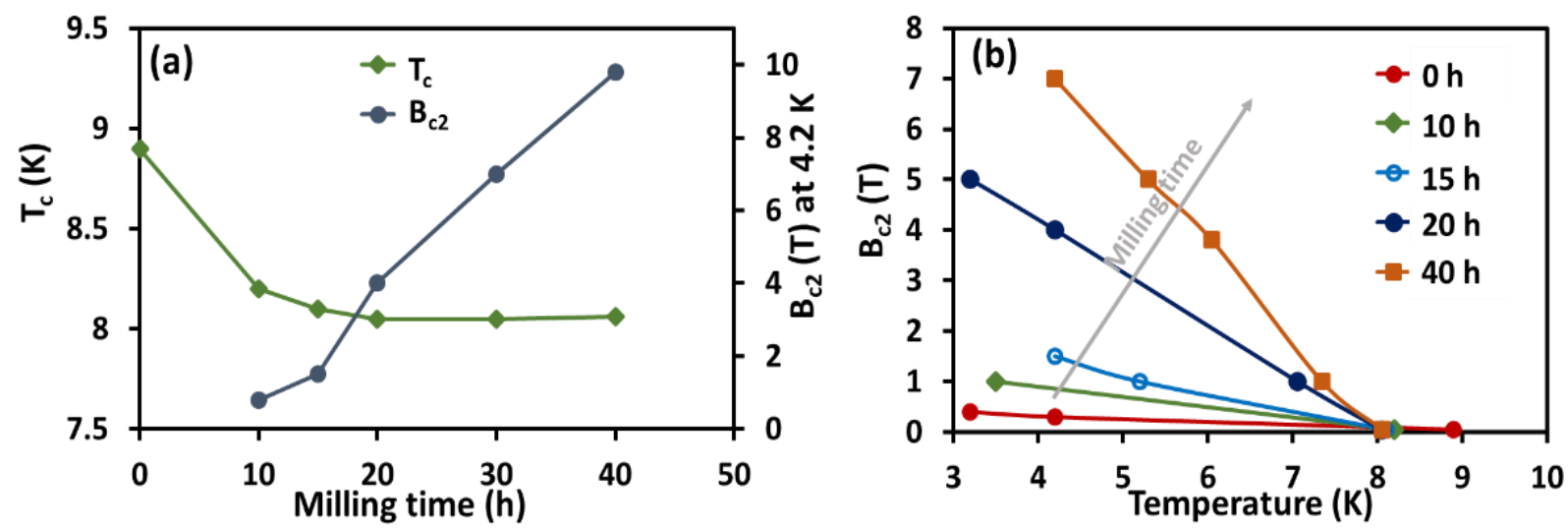

Figure 7: Superconducting parameters $\left(T_{c}\right.$ and $\left.B_{c 2}\right)$ measured by SQUID for Nb-Ti powder after different milling times (the $B_{c 2}$ value of the 40-hr milled powder was measured in a 16T-PPMS).

\section{3-2- Pressing and annealing}

In order to consolidate the mechanically alloyed $\mathrm{Nb}(\mathrm{Ti})$ into bulk material, powder milled for $40 \mathrm{hrs}$ was pressed at $200{ }^{\circ} \mathrm{C}$ and $400{ }^{\circ} \mathrm{C}$ at $40 \mathrm{MPa}$. These low temperatures were chosen to avoid the severe microstructural changes which will occur at high temperatures - specifically to avoid coarsening of the fine microstructure demonstrated in the as-milled powder. Sintering at $200^{\circ} \mathrm{C}$ results in weak bonding between NbTi powder particles and a high density of pores 
between the particles. The measured density of this sample is about $4.5 \mathrm{~g} / \mathrm{cm}^{3}$, only $60 \%$ of the theoretical value for $\mathrm{Nb}-47 \mathrm{wt} \% \mathrm{Ti}\left(6 \mathrm{~g} / \mathrm{cm}^{3}\right)$. However, pressing at $400^{\circ} \mathrm{C}$ leads to complete consolidation, with a high density of $5.95 \mathrm{~g} / \mathrm{cm}^{3}$ ( $99 \%$ of the theoretical value). As shown in Figure $8 \mathrm{~b}$ by red arrows, this material only contains a small number of pores, and there is little sign of boundaries between the individual starting particles. The 3D X-ray tomography images (taken by a North Star Instruments X5000 computed tomography instrument at $80 \mathrm{keV}$ X-ray energy) of a $4000 \mu \mathrm{m}^{3}$ volume of the bulk sample shows a small porosity fraction of about 3.4 vol\%. As shown by the circles in Figure 8b, there are also a few regions with a coarse $\mathrm{Nb} / \mathrm{Ti}$ layered microstructure which were not completely alloyed in the initial mechanical alloying process. The higher magnification BSE images in Figure 8(c), (d) and (e) are respectively from the 40-hr milled powder, and from poorly alloyed and completely alloyed regions after pressing at $400{ }^{\circ} \mathrm{C}$. The layered structure in the as milled powder in (c) has disappeared in (e), presumably as a result of refining the microstructure below the resolution limit of the BSE technique (see Figure 10 below).
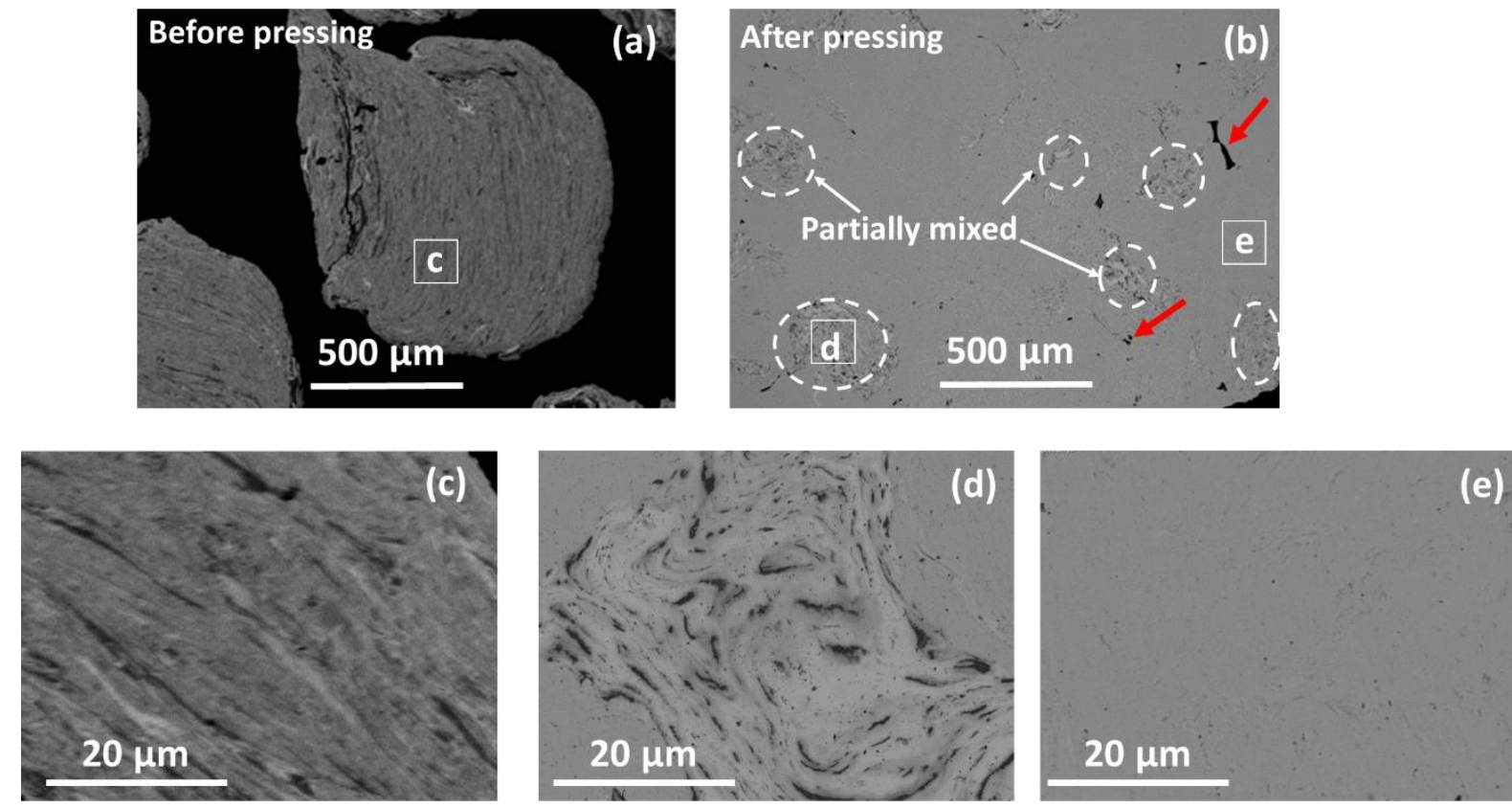

Figure 8: Back-scattered SEM images of the $40 \mathrm{hr}$-milled NbTi powder (a) before pressing and (b) after pressing at $400^{\circ} \mathrm{C}$ along with $(c),(d)$ and (e) higher magnification images from different regions indicated in $(a)$ and $(b)$. The red arrows show the pores and the white arrows show the partially mixed regions. 
These pressed samples were annealed for $2 \mathrm{hrs}$ at temperatures selected to be in different regions of the $\mathrm{Nb}$ - $\mathrm{Ti}$ phase diagram $\left(350,600\right.$ and $\left.1100{ }^{\circ} \mathrm{C}\right)$ with the aim of modifying the microstructure to optimise $\mathrm{J}_{\mathrm{C}}$. The treatment at $350{ }^{\circ} \mathrm{C}$ is just below the conventional range for precipitation of $\alpha-\operatorname{Ti}\left(375-420{ }^{\circ} \mathrm{C}\right)$ in multifilamentary wire fabrication, and was chosen to lie below the hot pressing temperature of $400{ }^{\circ} \mathrm{C}$ but not so far below to result in very slow diffusion kinetics. Figure $9 \mathrm{a}$ and $\mathrm{b}$ show magnetisation $\mathrm{J}_{\mathrm{c}}$ values and pinning force densities measured as a function of magnetic field for the $\mathrm{NbTi}$ samples after these heat treatments, compared to the as-pressed sample. Annealing at low temperature $\left(350{ }^{\circ} \mathrm{C}\right)$ leads to an enhancement in both $J_{c}$ and pinning force density relative to the as-pressed sample, whereas annealing at high temperatures $\left(600\right.$ and $\left.1100{ }^{\circ} \mathrm{C}\right)$ dramatically decreases both $\mathrm{J}_{\mathrm{c}}$ and pinning force.

The active pinning mechanism for these samples was explored using the Dew-Hughes model [32] by considering all the possible mechanisms and giving each a weighting parameter [33][34][35]. Details on how these calculations were performed can be found in [36]. The dominant pinning mechanism for all the samples was found to be surface normal pinning. However, it can be seen that the position of the peak in the pinning force density plot for the sample annealed at $350{ }^{\circ} \mathrm{C}$ shifts slightly towards higher magnetic fields (Figure 9b), indicating the introduction of a different pinning mechanism in this sample. For this sample, the analysis also suggests that in addition to surface normal pinning there is a small contribution of volume normal pinning, possibly as a result of the introduction of the fine-scale $\alpha$-Ti precipitates.

The transport $\mathrm{J}_{\mathcal{C}} / \mathrm{B}$ values for the sample annealed at $350^{\circ} \mathrm{C}$ (the highest $\mathrm{J}_{\mathrm{c}}$ measured by SQUID) were also measured and compared to values for NbTi multifilamentary wires from the literature (Figure 9c). For this measurement a thin NbTi ribbon (thickness $=120 \mu \mathrm{m}$ ) was fabricated as explained in the experimental section. The transport $\mathrm{J}_{\mathrm{c}}$ value of this NbTi ribbon shows a good consistency with both the $\mathrm{J}_{\mathrm{c}}$ measured by magnetisation at fields above $6 \mathrm{~T}$ (where the sample 
was damaged by excess current heating) and the value from the literature. For example, at $7 \mathrm{~T}$ the transport $\mathrm{J}_{\mathrm{c}}$ value is about $1.17 \mathrm{kA} / \mathrm{mm}^{2}$, the magnetisation $\mathrm{J}_{\mathrm{c}}$ value is $1.5 \mathrm{kA} / \mathrm{mm}^{2}$ and the literature $\mathrm{J}_{\mathrm{c}}$ value is $1.8 \mathrm{kA} / \mathrm{mm}^{2}$. The $\mathrm{B}_{\mathrm{c} 2}$ value of this annealed sample was measured to be 11.3 $\mathrm{T}$ by a field-sweep measurement at $4.2 \mathrm{~K}$ in the PPMS. This $\mathrm{B}_{\mathrm{c} 2}$ value is comparable with the commercial NbTi wires, and is higher than the $\mathrm{B}_{\mathrm{c} 2}$ value measured in the $40-\mathrm{hr}$ milled powder before pressing and annealing, perhaps due to the release of strain and improvement in structural order after annealing even at the relatively modest temperature of $350^{\circ} \mathrm{C}$. This indicates the potential of powder processing in fabricating $\mathrm{NbTi}$ with comparable superconducting properties to those commercially available NbTi wires but using a much simpler processing route.
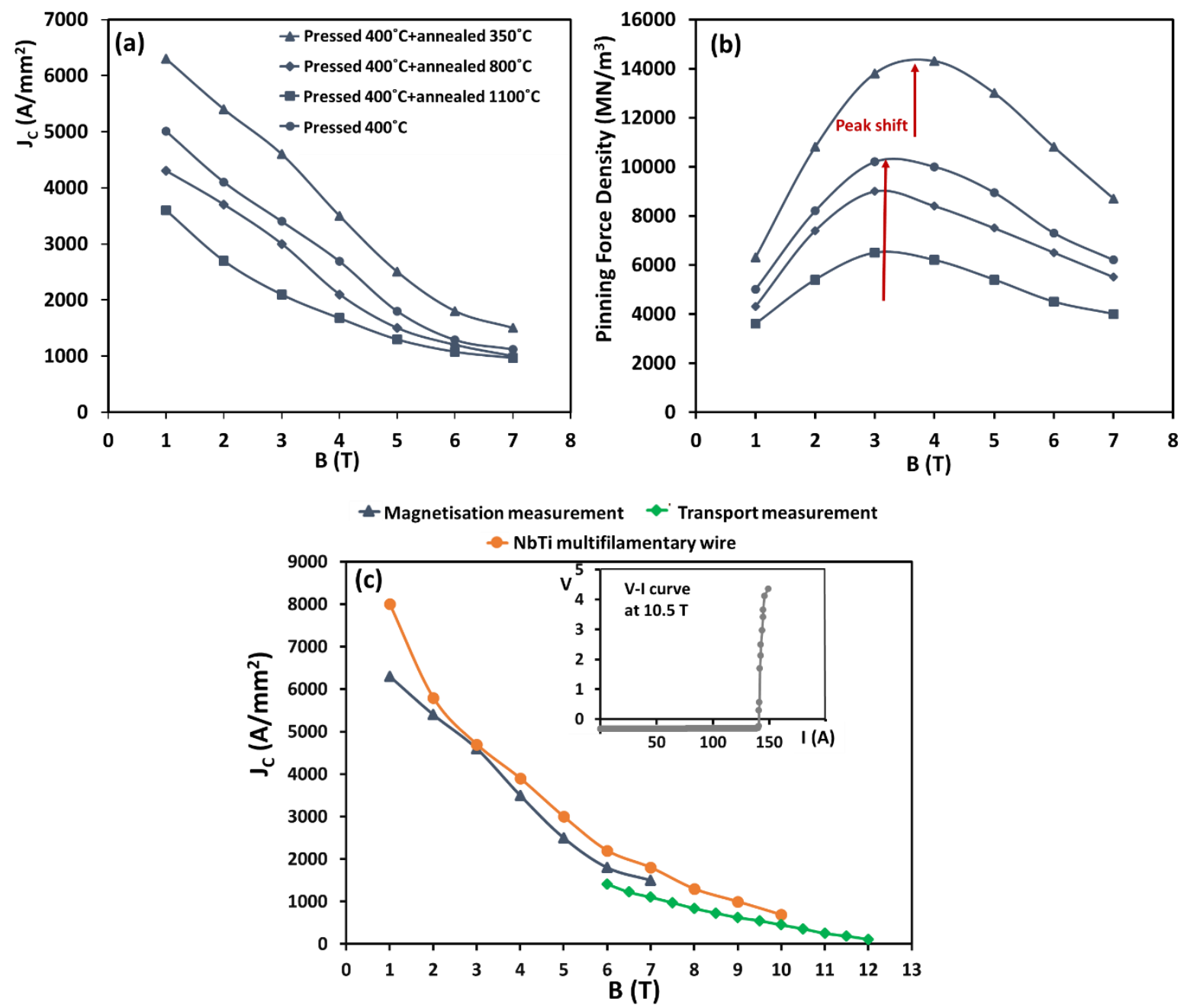

Figure 9: Superconducting properties of hot pressed $N b(T i)$ after different annealing processes. (a) Critical current density as a function of magnetic field at $4.2 \mathrm{~K}$, (b) pinning force density versus magnetic field, and (c) $J_{c}$ as a function of magnetic 
field for the sample annealed at $350^{\circ} \mathrm{C}$ measured from both magnetisation and transport measurements versus typical values for a multifilamentary NbTi strand (The best NbTi wire made at University of Wisconsin Madison [5]), For the transport measurement, the NbTi sample was made into a ribbon as explained in the experimental section. The inset of $(c)$ shows the $V$ I curve obtained from the transport measurement at $10.5 \mathrm{~T}$ ).

TEM images of the as-pressed sample and samples annealed at $350{ }^{\circ} \mathrm{C}$ and $1100{ }^{\circ} \mathrm{C}$ are shown in Figure 10. It can be seen that the microstructure of the sample annealed at $350{ }^{\circ} \mathrm{C}$ is still very fine, whereas the sample annealed at $1100^{\circ} \mathrm{C}$ shows more uniform microstructure with larger grains as a result of extensive grain growth at this higher temperature. Typical transmission electron diffraction patterns from these samples (Figure 10d-f) indicate substantial grain growth in the sample annealed at $1100{ }^{\circ} \mathrm{C}$, as shown by the separate diffraction spots (Figure 10f) compared to the continuous diffraction rings (Figure 10d and e). The diffraction pattern of the as-pressed sample only has rings from $\beta$-NbTi phase.

According to the $\mathrm{Nb}$-Ti binary phase diagram [25], a single $\beta$-phase region exists above 600 ${ }^{\circ} \mathrm{C}$ for the $\mathrm{Nb}-47 \mathrm{wt} \% \mathrm{Ti}$ alloy, and a two- phase $(\alpha+\beta)$ region below $600{ }^{\circ} \mathrm{C}$. We thus expect that when our consolidated material is annealed at $350{ }^{\circ} \mathrm{C}$ (in the two-phase region), further precipitation of $\alpha$-Ti will occur from supersaturated $\beta-\mathrm{Nb}(\mathrm{Ti})$. The TEM image in (Figure 10b) shows that the microstructure is indeed significantly refined by this low temperature anneal, and the corresponding diffraction pattern shows extra inner ring consistent with some $\alpha$-Ti phase in addition to the $\beta$-NbTi. The APT data in Figure 11 confirms the presence of nanoscale Ti stripes (with a composition of $97.5 \% \mathrm{Ti}$ and thickness of $5-30 \mathrm{~nm}$ ) within a $\beta-\mathrm{Nb}(\mathrm{Ti}$ ) matrix with a composition of about $\mathrm{Nb}-45 \mathrm{wt} \% \mathrm{Ti}$. A previous study has shown that heat treatments at $405^{\circ} \mathrm{C}$ produced $\alpha$-Ti precipitates at grain boundaries [37], and in this work the initial microstructure of the $\mathrm{Nb}(\mathrm{Ti}$ ) alloy achieved by milling (Figure 6) has a grain size of about $50 \mathrm{~nm}$. This creates a large density of grain boundary triple points uniformly distributed in the sample which are ideal locations for $\mathrm{Ti}$ precipitation during the low temperature annealing stage. Moreover, because diffusion is very slow in $\mathrm{Nb}-\mathrm{Ti}$ system at this low 
temperature [1], the $\alpha$-Ti precipitates remain very fine and do not coarsen. This correlates well with the peak shift in the pinning force density plot, the presence of the second pinning mechanism and high pinning force density in this sample, as discussed earlier and in Figure 9. We have also measured the oxygen content in the 2 phases by APT, showing about $4-5$ at $\%$ in the Ti-rich volumes and less than 1 at $\%$ in the $\mathrm{Nb}(\mathrm{Ti})$ alloyed regions. We assume that this $\mathrm{O}$ content is a result of the small batch powder processing, and could be reduced in a scaled-up manufacturing process to avoid the stabilisation of excess $\alpha$-Ti. Low concentrations of $\mathrm{N}, \mathrm{Ni}$ and $\mathrm{Fe}(<0.5$ at $\%)$ were also detected in the APT data - mostly segregated to the $\mathrm{Nb}(\mathrm{Ti})$ phase. We believe that this is the first time that APT has been used to give this kind of detail on the trace element concentrations at the nanoscale in NbTi superconductors.

When the sample is annealed at $1100^{\circ} \mathrm{C}$, the microstructure becomes more uniform and much coarser, which results from a much higher diffusion rate at this temperature leading to the formation of the stable $\beta$ phase with larger grains, less strain and fewer structural defects. Because the active pinning mechanism is surface normal, for this larger grained sample it is not surprising that the pinning force density and the $J_{c}$ value are both lower than either the sample annealed at $350{ }^{\circ} \mathrm{C}$ or the as-pressed sample. Even annealing at an intermediate temperature of $600{ }^{\circ} \mathrm{C}$ significantly degrades the superconducting properties of the pressed material (Figure 9). 

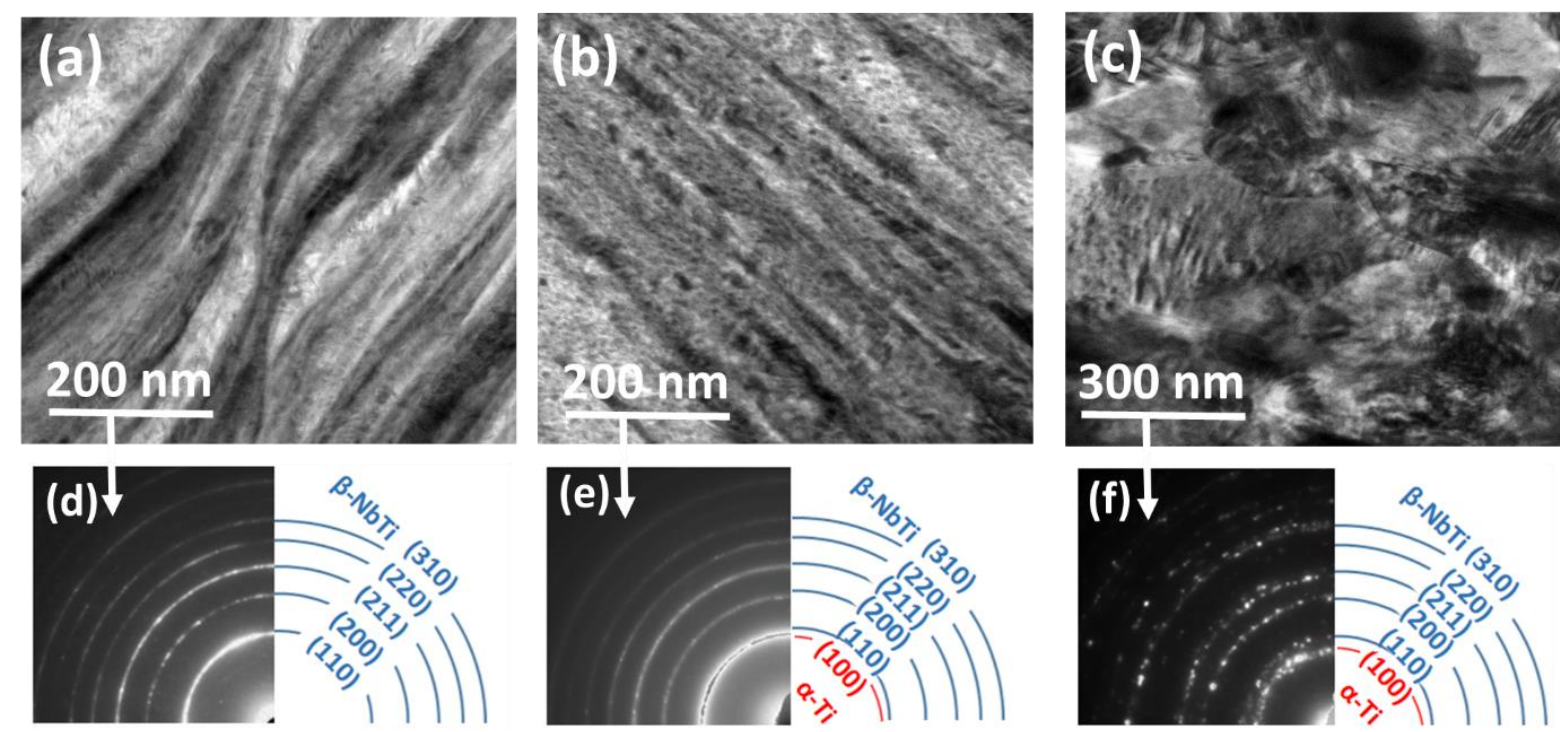

Figure 10: Bright-field TEM images of NbTi samples after (a) pressing at $400^{\circ} \mathrm{C}$, (b) pressing and annealing at $3500^{\circ} \mathrm{C},(\mathrm{c})$ pressing and annealing at $1100^{\circ} \mathrm{C},(d-f)$ corresponding diffraction patterns of the samples $(a-c)$.
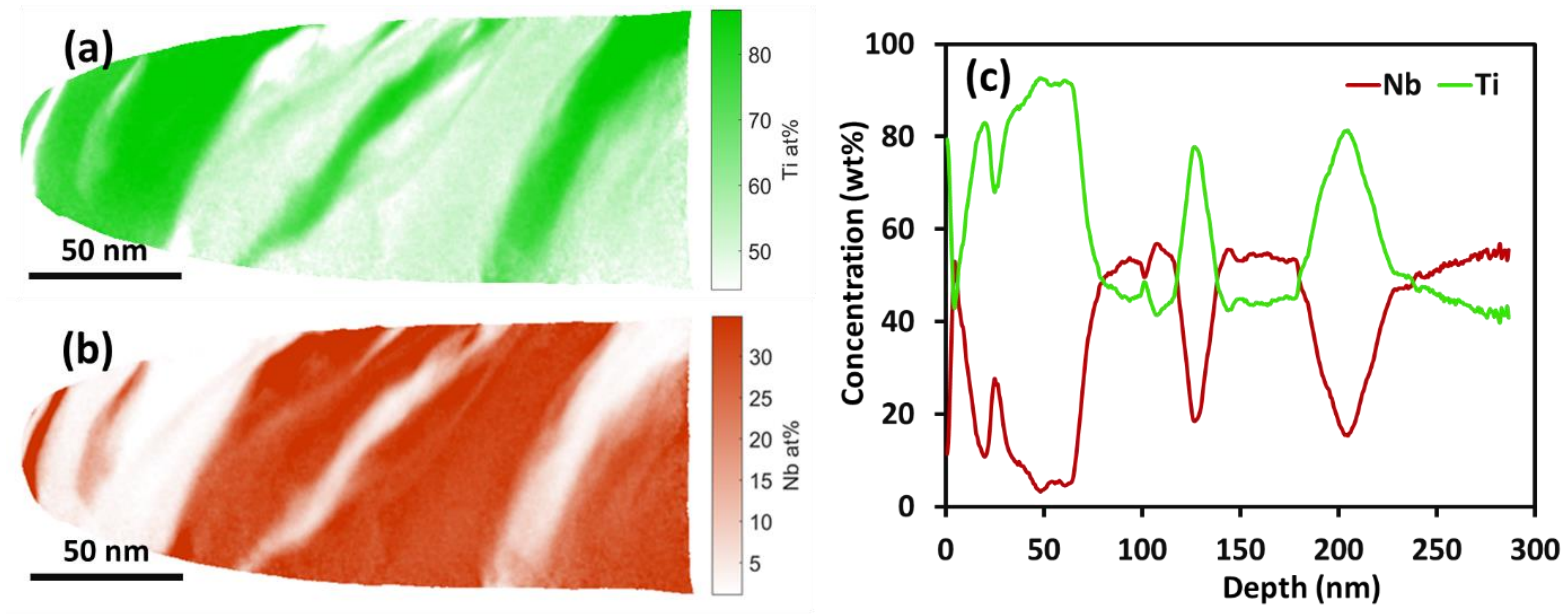

Figure 11: (a,b) Atom probe reconstructions of the $\mathrm{Nb}$ and Ti maps in the Nb(Ti) sample after pressing and annealing at 350 ${ }^{\circ} \mathrm{C}$ showing the presence of nano-scale Ti precipitation within a matrix with a composition of about $\mathrm{Nb}-45 \mathrm{wt} \% \mathrm{Ti}$,

(c) Average composition line profiles across the stripes in the the $\mathrm{Nb}(\mathrm{Ti})$ sample after pressing and annealing at $350^{\circ} \mathrm{C}$.

\section{4- Conclusions}

Bulk superconducting $\mathrm{Nb}(\mathrm{Ti})$ alloy samples have been successfully fabricated by ball-milling pure $\mathrm{Nb}$ and $\mathrm{Ti}$ powders at room temperature, a simple processing route compared to the thermo-mechanical process used in industry. The $\mathrm{Nb}$-Ti system has been shown to be suitable for ball-milling such that a fine-grained superconducting $\mathrm{Nb}(\mathrm{Ti})$ powder with uniform composition is formed in $40 \mathrm{hrs}$ in a single process. However, when a stainless steel milling 
media is used, the powder yield is less than $50 \%$ due to cold-welding of ductile $\mathrm{Nb}$-Ti powders to the milling pot. This may be improved by the use of alternative milling media. Ball-milling of this system leads to the formation of uniform fine grains of $\beta-\mathrm{Nb}(\mathrm{Ti})$ containing $\sim 50 \mathrm{wt} \% \mathrm{Ti}$ as the majority phase in the microstructure with small stripes of pure $\alpha$-Ti or dilute $\beta$-Ti(Nb), and a high density of strain and structural defects which create well- distributed potential locations for further $\alpha$-Ti precipitation during subsequent low temperature annealing. Due to the non-equilibrium nature of ball-milling, the mutual solid solubility ranges of both elements is expanded leading to a relatively high $\mathrm{Nb}$ content in the Ti regions and larger thermodynamic driving force for $\alpha$-Ti precipitation in a subsequent heat treatment process.

The milled $\mathrm{Nb}(\mathrm{Ti})$ powders are easily consolidated into a bulk sample by pressing at $400{ }^{\circ} \mathrm{C}$. Subsequent annealing at low temperatures $\left(\mathrm{T}<600{ }^{\circ} \mathrm{C}\right)$ leads to phase separation at a very fine scale and further precipitation of $\alpha$-Ti which we suggest results in an enhancement in $J_{c}$ values and pinning force density. Superconducting properties have been measured in consolidated bulk samples of the milled product with $\mathrm{J}_{\mathrm{c}}$ and $\mathrm{B}_{\mathrm{c} 2}$ values comparable with those of conventionally processed $\mathrm{NbTi}$ wires. A nanometer-scale layered microstructure with some similarities to those achieved in $\mathrm{Nb}$ - $\mathrm{Ti}$ wires has been shown to arise naturally from the intrinsic processes involved in mechanical alloying, and strong pinning has been demonstrated in our consolidated $\mathrm{Nb}(\mathrm{Ti})$ material. Of course, these bulk materials will have to be subsequently processed by wire-drawing with inter-stage annealing to single filaments, stacking and final extrusion to multifilamentary wires in the normal way, and this will further modify the microstructure.

As a conclusion, we suggest that mechanical alloying should be further explored as a potential process to produce high quality $\mathrm{Nb}(\mathrm{Ti})$ powder which can be easily pressed into ingots that may prove a competitive precursor to the expensive melt-processed billet material currently used in the manufacturing of $\mathrm{Nb}-\mathrm{Ti}$ wire. 


\section{Acknowledgements}

This research was funded by Centre for Applied Superconductivity (CFAS) at Oxford University. The authors gratefully acknowledge Dr Clara Barker, Dr Greg Brittles, Matthew Bristow and Robert Gresham for their assistance. We are also grateful to the reviewers of this manuscript for their constructive comments that have assisted us to improve the paper. Data in support of this paper is accessible on the Oxford Research Archive (www.ora.ox.ac.uk) doi: 10.5287/bodleian:j1g7Kbj4d.

\section{References}

[1] P. J. Lee, "Abridged Metallurgy of Ductile Alloy Superconductors," Wiley Encycl. Electr. Electron. Eng., 1999.

[2] M. A. Tirelli, C. B. Nunes, and L. Ghivelder, "Nb-Ti superconductor wires with $\mathrm{Cu}$ as artificial pinning centers," Phys. C Supercond., vol. 408-410, pp. 201-203, Aug. 2004.

[3] D. A. Cardwell and D. S. Ginley, Handbook of Superconducting Materials. CRC Press, 2002.

[4] J. F. Li, P. X. Zhang, X. H. Liu, J. S. Li, Y. Feng, S. J. Du, T. C. Wang, W. T. Liu, G. Grunblatt, C. Verwaerde, and G. K. Hoang, "The microstructure of NbTi superconducting composite wire for ITER project," Phys. C Supercond., vol. 468, no. 15-20, pp. 1840-1842, 2008.

[5] D. C. Larbalestier and P. J. Lee, "New development in NbTi superconductors," Applied Superconductivity Center, University Of Wisconsin-Madison, Madison, WI 53706 USA, 1996. DOI: 10.1109/PAC.1995.505199.

[6] R. W. Heussner, "Magnetization critical current density of conventional and artificial pinning center (APC) NbTi superconducting wires," J. Magn. Magn. Mater., vol. 230, pp. 298-300, 2001.

[7] P. J. Lee and D. C. Larbalestier, "Determination of the flux pinning force of Ti ribbons in $\mathrm{Nb} 46.5 \mathrm{wt} \%$ Ti produced by heat treatments of varying temperature, duration and frequency," $J$. Mater. Sci., vol. 23, no. 11, pp. 3951-3957, 1988.

[8] E. W. Collings, A Sourcebook of Titanium Alloy Superconductivity. Springer US, 1983.

[9] D. Larbalestier, "The metallurgical design of $\mathrm{Nb}-\mathrm{Ti}$ and $\mathrm{Nb}_{3} \mathrm{Sn}$ multifilament superconductors," IEEE Transactions on Magnetics, vol. 15, no. 1. pp. 209-212, 1979.

[10] H. B. Ouyang, J. F. Li, T. C. Wang, Y. X. Xue, X. B. Wan, Y. Fang, F. S. Zhang, G. Yan, X. H. Liu, Y. Feng, and P. X. Zhang, "Influence of Final Drawing Strain on the $J_{c}$ of NbTi Superconductor," IEEE Trans. Appl. Supercond., vol. 22, no. 3, pp. 6001003-6001003, Jun. 2012.

[11] J. Somerkoski, C. F. Zignani, G. De Marzi, and L. Muzzi, "Metallurgical Processes in NbTi Filaments as a Function of Isothermal Annealing Time," Phys. Procedia, vol. 36, pp. 1516$1521,2012$.

[12] C. F. Zignani, G. De Marzi, L. Muzzi, and J. Somerkoski, "Evolution of the Pinning Force of NbTi Filaments as a Function of Isothermal Annealing Time," Phys. Procedia, vol. 36, pp. 
1406-1411, 2012.

[13] J. W. N. Prasan K. Samal, ASM Handbook, Volume 7: Powder Metallurgy. ASM International, 2015.

[14] Y. J. Liang, X. Cheng, and H. M. Wang, "A new microsegregation model for rapid solidification multicomponent alloys and its application to single-crystal nickel-base superalloys of laser rapid directional solidification," Acta Mater., vol. 118, pp. 17-27, Oct. 2016.

[15] C. Suryanarayana, "Mechanical alloying and milling," Prog. Mater. Sci., vol. 46, no. 1-2, pp. 1-184, 2001.

[16] C. Suryanarayana, Mechanical Alloying And Milling (Mechanical Engineering). CRC Press, 2004.

[17] T. Mousavi, F. Karimzadeh, and M. H. Abbasi, "Synthesis and characterization of nanocrystalline NiTi intermetallic by mechanical alloying," Mater. Sci. Eng. A, vol. 487, no. 12, pp. 46-51, 2008.

[18] P. R. Soni, Mechanical Alloying: Fundamentals and Applications. Cambridge: ambridge Int Science, 2000.

[19] Y. A. Giffoni, E. C. T. Ramos, H. R. Z. Sandim, M. T. T. Pacheco, G. Silva, and A. S. Ramos, "Structural Evaluation of Mechanically Alloyed Ti-Nb Powders," Mater. Sci. Forum, vol. 591593, pp. 141-146, 2008.

[20] K. Zhuravleva, S. Scudino, M. S. Khoshkhoo, A. Gebert, M. Calin, L. Schultz, and J. Eckert, "Mechanical alloying of $\beta$-type Ti-Nb for biomedical applications," Adv. Eng. Mater., vol. 15, no. 4, pp. 262-268, 2013.

[21] G. K. Williamson and W. H. Hall, "X-ray line broadening from filed aluminium and wolfram," Acta Metall., vol. 1, no. 1, pp. 22-31, 1953.

[22] M. K. Miller and Y. Zhang, "Fabrication and characterization of APT specimens from high dose heavy ion irradiated materials," Ultramicroscopy, vol. 111, no. 6, pp. 672-675, 2011.

[23] C. P. Bean, "Magnetization of High-Field Superconductors," Rev. Mod. Phys., vol. 36, no. 1, pp. 31-39, Jan. 1964.

[24] Y. A. Giffoni, E. C. T. Ramos, H. R. Z. Sandim, and M. T. T. Pacheco, "Structural evaluation of mechanically alloyed Ti-Nb powders," Mater. Sci. Forum, vol. 591, p. 141, 2008.

[25] A. K. Mallik, "Computer calculations of phase diagrams," Bull. Mater. Sci., vol. 8, no. 2, pp. 107-121, 1986.

[26] S. K. Pabi and B. S. Murty, "Mechanism of mechanical alloying in Ni-Al and Cu-Zn systems," Mater. Sci. Eng. A, vol. 214, no. 1-2, pp. 146-152, 1996.

[27] S. Martelli, G. Mazzone, and M. Vittori-Antisari, "The effect of plastic deformation at near room temperature on the solid state reactions between Ni and Sn," J. Mater. Res., vol. 6, no. 3, pp. 499-504, 1991.

[28] S. Buga, G. Dubitsky, N. Serebryanaya, V. Kulbachinskii, and V. Blank, Applications of High$T_{c}$ Superconductivity. InTech, 2011.

[29] A. N. Omran, K. Do Woo, E. P. Kwon, N. A. Barakat, H. B. Lee, S. W. Kim, and D. Zhang, "Fabrication of Biocompatible Ti-Nb-Sn Alloy by Pulsed Current Activated Sintering Using High Energy Ball Milled Powder," Science of Advanced Materials, vol. 1, no. 2. pp. 205-211.

[30] Y. Wang, Fundamental Elements of Applied Superconductivity in Electrical Engineering. Wiley-Blackwell, 2014. 
[31] Y. Obi, S. Takahashi, H. Fujimori, M. Ikebe, and H. Fujishiro, "Superconducting properties of NbTi based multilayers," J. Low Temp. Phys., vol. 96, no. 1-2, pp. 1-18, 1994.

[32] D. Dew-Hughes, "Flux pinning mechanisms in type II superconductors," Philos. Mag., vol. 30, no. 2, pp. 293-305, 1974.

[33] M. H. Pu, Y. Feng, P. X. Zhang, L. Zhou, and J. X. Wang, "Investigating the flux pinning in high temperature superconductors more accurately," Phys. C Supercond., vol. 386, pp. 47-51, 2003.

[34] L. Muzzi, L. Muzzi, G. De Marzi, C. F. Zignani, L. Affinito, M. Napolitano, R. Viola, C. O. Domínguez, L. Bottura, S. Le Naour, D. Richter, and A. Corte, "Pinning Properties of Commercial Nb-Ti Wires Described by a 2-Components Model," no. September 2016, pp. 2-6, 2010.

[35] C. Meingast and D. C. Larbalestier, "Quantitative description of a very high critical current density $\mathrm{Nb}$-Ti superconductor during its final optimization strain. II flux pinning mechanisms," Journal of Applied Physics, vol. 66, n. 12, p. 5971, 1990.

[36] T. Mousavi, C. Aksoy, C. R. M. Grovenor, and S. C. Speller, "Microstructure and superconducting properties of Sn-In and Sn-In-Bi alloys as Pb-free superconducting solders," Supercond. Sci. Technol., vol. 29, no. 1, p. 15012, 2016.

[37] P. J. Lee and D. L. Larbalestiert, "Development of nanometer scale structures in composites of $\mathrm{Nb}-\mathrm{Ti}$ and their effect on the superconducting critical current density," Acta Metall., vol. 35, no. 10, pp. 2523-2536, 1987. 